\title{
COMPARISON IN BENEFITS OF HERBAL MOUTHWASHES WITH CHLORHEXIDINE MOUTHWASH: A REVIEW
}

\author{
RENUKA S ${ }^{1 *}$, MURALIDHARAN NP² \\ ${ }^{1}$ Department of Microbiology, Saveetha Dental College and Hospitals, Chennai, Tamil Nadu, India. ${ }^{2}$ Department of Microbiology, Saveetha \\ Dental College and Hospitals, Chennai, Tamil Nadu, India. Email: renuka2602@gmail.com
}

Received: 06 June 2016, Revised and Accepted: 08 November 2016

\section{ABSTRACT}

Objective: To discuss the benefits of herbal mouthwashes with the standard chlorhexidine mouthwash. This review is conducted to explore the benefits of herbal mouthwashes.

Methods: Many herbal extracts are now available as mouthwash for maintaining the good oral hygiene. Plaque accumulation and increase in oral microorganisms are the main factors for poor oral hygiene. Herbal extracts such as German chamomile, Terminalia chebula, Aloe vera, Green tea, peppermint satva, turmeric, neem, triphala, pomegranate extracts, guava extract, propolis, alum, darim leaves, mulethi, etc., are similar to chlorhexidine in plaque control and gingivitis reduction. Many herbal mouthwashes contain herbs with anti-microbial property such as neem, yavani satva, nagavalli, Gandhapura taila, pilu, Bibhitaka, Ocimum, Echinacea, Chameli leaves, etc. Many herbs are with anti-inflammatory and anti-oxidant property such as neem, clove, triphala (combination of amalaki, haritaki, and vibhitaki), tulsi, grapefruit, celery, licorice, katha, spearmint, and chamomile essential oil. Some herbal mouthwash with chamomile extract kills some skin pathogens such as staphylococcus and Candida species. Mixture of Staphysagria, Chamomilla, Echinacea, Plantago, Ocimum, and Cistus extracts used as mouth wash which was is better than chlorhexidine in reducing salivary mutans streptococci count. Hence usage of herbal mouthwash will enhance the oral hygiene comparatively with chlorhexidine mouthwash without any adverse effects.

Result: Though herbal mouthwashes has the ability to maintain good oral hygiene on daily basis, but still it is less effective than chlorhexidine mouthwash during treatments like gingivitis, periodontitis, trauma, etc.

Conclusion: Besides the disadvantages, chlorhexidine mouthwash plays effective role during dental treatments on short term usage. Herbal mouthwashes are suitable for maintaining good oral prophylaxis. Many programs have to be conducted to make them aware about mouthwashes in their oral hygiene.

Keywords: Chlorhexidine, Herbal, Mouthwash, Oral hygiene, Prophylaxis.

(C) 2017 The Authors. Published by Innovare Academic Sciences Pvt Ltd. This is an open access article under the CC BY license (http://creativecommons. org/licenses/by/4. 0/) DOI: http://dx.doi.org/10.22159/ajpcr.2017.v10i2.13304

\section{INTRODUCTION}

The primary aim of this review is to find an alternative to chlorhexidine mouthwash - A gold standard mouthwash which is prescribed by most of the dentist during treatments like gingival inflammation and periodontal diseases. Susceptibility to dental and periodontal disease depends on risk factors includes genetics, systemic factors, and oral hygiene [1]. Plaque is the primary cause for gingivitis [2]. Most of the chemical products contain an antiseptic that plays an important role in controlling plaque accumulation. The vehicles for delivery of chemical agents with anti-plaque action are toothpaste, mouthwashes, spray, irrigators, chewing gums, and varnishes [3]. However, mostly accepted method of delivering the anti-microbial agents after toothpaste is mouthwashes [4]. Mouthwashes are an antiseptic solution which is used to reduce the microbial load in the oral cavity. Mouth rinses have the ability to deliver the therapeutic effect all over the tooth surface including interproximal areas in which even toothpastes are not much effective [5]. Even though, chlorhexidine mouthwash is more effective in plaque control, it cannot be used for long duration because some of its unpleasant side-effects after long duration usage pays more attention toward herbal drugs. Plants and plant extracts demonstrate effects that are immune enhancing, anti-inflammatory, anti-cancer, etc. [6]. This review will discuss in detail about the benefits of herbal mouthwash in comparison with standard chlorhexidine mouthwash.

\section{MOUTHWASH}

Mouthwashes are liquids which contain anti-inflammatory, antimicrobial, and analgesic action. There are two types of mouthwash - chemical and herbal. Chlorhexidine mouthwash comes under chemical mouthwash. Chlorhexidine was developed in 1950, which is still considered the most effective anti-plaque agents in dentistry [7]. Many of the plant extracts has an anti-microbial property which is effectively used in maintaining good oral hygiene. Natural herbs such as triphala, tulsi patra, jyestiamadh, neem, clove oil, pudina, and many others are used as single or in combination have been scientifically proven to be safe and effective medicine against oral health problems such as bleeding gums, halitosis, mouth ulcers, and preventing tooth decay without side effects [8]. The main purposes of using mouthwashes are it can be used at home as routine to maintain good oral hygiene, mouthwash provides anti-inflammatory, anti-microbial activity, it is used prior to and after oral surgery procedures such as tooth extraction as prophylaxis, the purpose of mouthwash after brushing is to clean the areas which cannot be reached during brushing, It freshens the mouth by which it helps to control bad breath, and it kills all germs that have not killed by toothpaste.

\section{CHEMICAL MOUTHWASH}

Chlorhexidine mouthwash is the gold standard mouthwash which is good example for chemical mouthwash. It is a cationic polybiguanide. It is basically antibacterial used as an antiseptic and for other applications. A variety of products are available chemical plaque control, which is divided into the first generation (e.g., phenols, quaternary ammonium compounds), second generation (e.g., bisbiguanides-chlorhexidine gluconate [CHXG]), and third generation (e.g., delmopinol) [9]. Chlorhexidine is an important ingredient in mouthwashes to reduce plaques accumulation and bacterial 
growth. Hence, it is used during the treatments such as gingivitis, periodontitis, trauma, and after wisdom tooth extraction.

\section{Mode of action}

Chlorhexidine is a broad-spectrum biocide effective against Grampositive bacteria, Gram-negative bacteria, and fungi. Depending on its concentration, it has both bacteriostatic (inhibits bacterial growth) and bactericidal (kills bacteria) mechanisms of action. Chlorhexidine kills the microorganism by disrupting the cell membrane [10]. Positively charged chlorhexidine attracted toward negatively charged phospholipids in the cell wall and causes rupture which leads to lysis of cytoplasm and end up in cell death. On application in vitro, chlorhexidine can kill nearly $100 \%$ of Gram-positive and Gram-negative bacteria within 30 seconds [11].

It provides immediate bactericidal and prolonged bacteriostatic action due to adsorption onto the pellicle-coated enamel surface [12]. Chlorhexidine is active against Gram-positive, Gram-negative, facultative anaerobes, aerobes, and yeasts [13]. Chlorhexidine is ineffective against poliovirus and adenovirus. Since chlorhexidine formulations can destroy the majority of categories of microbes, there is limited risk for the development of opportunistic infections.

In topical applications, chlorhexidine is shown to have the unique ability to bind with the proteins present in human tissues such as skin and mucous membranes with limited systemic or bodily absorption [14]. Protein-bound chlorhexidine releases slowly leading to prolonged activity. This phenomenon is known as substantivity [15] and allows for a longer duration of antimicrobial action against a broad spectrum of bacteria and fungi. In fact, chlorhexidine antimicrobial activity has been documented to last at least 48 hours on the skin [16].

In oral applications, chlorhexidine binds to the mouth tissue, oral mucosa, and teeth. This helps to reduce the bacterial count and prevents dental plaque. It has become the gold standard in dentistry due to its ability to adhere to soft and hard tissue and maintain a potent sustained release [17]. Chlorhexidine has also been applied to medical devices such as dental implants, vascular catheters, needleless connectors and anti-microbial dressings. Chlorhexidine, when applied to or impregnated in medical devices protects against microbial colonization and subsequently biofilm development

The overdose of chlorhexidine may cause nausea, vomiting, feel like drunken, etc. It may also leads to some side effects such as white patches in mouth or lips, ulcers, swelling of salivary glands, irritation, dry mouth, unpleasant taste, decreased sensation due to an allergic reaction to some individuals.

Although chlorhexidine mouthwash has some side effects being a gold standard mouthwash it is effective in maintaining good oral hygiene during gingivitis, periodontitis, traumas [18], oral cyst [19] and after wisdom tooth extraction. It lasts longer in the mouth than other mouthwashes. It is required for healing and regeneration of oral tissues. However, continuous use of products containing chlorhexidine for long periods can cause stains on teeth, tongue and gingiva also on silicate and resin restorations, alter taste sensation, sweeping, xerostomia, ulcers, etc. Hence, it cannot be used for daily prophylactic measures.

Other chemical mouthwashes are made of potassium nitrate, hydrogen peroxide, iodide, etc. Some of the harmful chemicals in mouthwashes are thymol, hexetidine, methyl salicylate, eucalyptol, benzalkonium chloride, cetylpyridinium, chloride, methyl paraben, alcohol, and hydrogen peroxide which causes harmful effects in our body.

Iodine-based mouth rinse was clearly effective in reducing the amount of harmful bacteria in the mouth when used daily. However, the most interesting part is that it significantly lowers cholesterol levels in the patients. In addition to iodine's strong antibacterial and antifungal properties, which make it an ideal mouth rinse which is available in markets. In a recent study, the effect of povidone-iodine and chlorhexidine mouthwash is compared on plaque Streptococcus mutans count after restoration. After using mouth rinse, there was a significant reduction in $S$. mutans count in the population. After 3 months interval, the count started to gradually increase with iodine mouth rinse [20].

Hydrogen peroxide is a liquid substance which is also commonly used as a mouthwash. It works to destroy bacteria via oxidation damage. This oxidation creates free-radicals which can ultimately destabilize the molecular structure and cellular strength of the bacteria cells. Hydrogen peroxide is also used in teeth bleaching agents to whiten your teeth. However, this does not mean that hydrogen peroxide will be effective at whitening your teeth. The amount of hydrogen peroxide you use determines the safety of the mouthwash. The problem with hydrogen peroxide is that it has a cytotoxic effect on the dental pulp cells, which means that it literally kills them.

Alkaline mouthwash is predominantly used as mouthwash. It helps in eliminating bad breath, soothes mouth ulcers, restores $\mathrm{pH}$ balance, reduces acidity, low alcohol content, and reduces stinging and burning.

The use of sodium bicarbonate as a mouthwash helps in patients with suffering from xerostomia or erosion due to its ability to increase salivary $\mathrm{pH}$ and suppress the growth of acid producing microorganisms such as $S$. mutans and also helps in treatment for mouth ulcers [21,22].

This medication is used to prevent cavities and to reduce pain from sensitive teeth (dentinal hypersensitivity). Sodium fluoride works by making the teeth stronger and more resistant to decay caused by acid and bacteria. Potassium nitrate works by calming the nerves in the teeth. Mouth/gum irritation may rarely occur.

\section{HERBAL MOUTHWASH}

Herbal mouthwash contains a natural ingredients called phytochemical that contains desired anti-microbial and anti-inflammatory effect. Herbal mouthwash becomes more popular they work without alcohol, artificial preservatives, flavor, or colors [5]. As it contains natural herbs that have natural cleansing and healing property to teeth and gums. Many herbal mouthwashes contain herbs with anti-microbial property such as Neem, Yavani satva, Nagavalli, Gandhapurataila, Pilu, Bibhitaka, Ocimum, Echinacea, Chameli leaves, etc [23]. Some of the herbs that are used in mouthwashes are clove, which is traditionally used for oral health because of their antiseptic, antibacterial, and antiviral property, peppermint which gives cooling effect to the mouth, plantain has ability for speed wound healing and many of the herbs contains anti-microbial, anti-inflammatory, antioxidants, antiseptic properties such as neem, clove, triphala with combination of amalaki, haritaki, vibhitaki, tulsi, celery, licorice, oak tree, bakula, katha, spearmint, turmeric, and Aloe vera. [5].

Almost all chemical mouthwashes contain alcohol and fluoride which is toxic to our body in overdose. Hence, most herbal mouthwashes are safe alternative to pregnant women, people with dry mouth, diabetic and to children. Instead of artificial dyes, herbal mouthwash made of vegetable juices such as beetroot, tomato, carrot, and annatto to add color.

Vegetable glycerine, stevia, and xylitol are used as a sweetener in which foster bacteria does not grow. Vegetable glycerine is derived from soy, and it is clear, colorless, and odorless liquid with an incredibly sweet taste used as an agent in toothpaste, cosmetics, shampoos, soaps, herbal remedies, pharmaceuticals, and other household items. Because it is soluble in water and alcohol which also that aids herbalists in extracting botanical properties from plant materials without the use of alcohol. Stevia is a natural sweet herb used by diabetic patient and it also inhibits the growth and reproduction of some bacteria and other infectious organisms, including the bacteria that cause tooth decay and gum disease. Xylitol is a natural sweetener which helps to improve the dental health, to prevent bacteria from sticking to teeth and also freshens the breath and cleans the mouth. Essential oils used to freshen 
the breath in the mouth. It enhances the mineral absorption in enamel and thus increases the strength of the tooth.

Many fruit extracts such as pomegranate, guava, cranberry, grapefruit and, which is used in mouthwashes which contain medicinal properties.

Guava (Psidium guajava) as a mouthwash for swollen gums and ulceration of the mouth and also for bleeding gums [24].

Pomegranate extract containing mouthwash may fight dental plaque and tartar formation by inhibiting the activities of the microorganisms that causes plaque, and it also suppresses the ability of the microorganism to adhere to the tooth structure [25]. Polyphenolic flavonoids are believed to prevent gingivitis through a number of mechanisms including reduction of oxidative stress in the oral cavity which is a active component of pomegranate [26-28]. Pomegranate extract can reduce the signs of chronic periodontitis [29].

Neem as mouthwash has been shown to have significant effects on both Gram-positive and Gram-negative organisms which include Escherichia coli, streptococcus, and salmonella. Extracts from neem inhibit the growth of $S$. mutans and used in the treatment of periodontitis [30]. It contains anti-microbial, anti-inflammatory, and anti-oxidant property.

Tulsi (Ocimum sanctum) as a mouthwash Is quite effective for the ulcer and infections in the mouth. It also helps in eliminating bad breath; also prevent gum disorder [31] as it has anti-oxidant and anti-inflammatory property.

Green tea (Camellia sinensis) can be used as a gargle or mouthwash to treat dental decay, halitosis, laryngitis, mouth sores, plaque formation, sore throat, thrush, tonsillitis and helps in controlling dental plaque accumulation and free from side effects [32].

Bee propolis has proved successful against dental disorders such as plaque accumulation, cavities, gum disease and mouth ulcers, as well as acute and chronic periodontitis [30]

Table 1 shows that comparison of herbs based on their antiinflammatory, antibacterial, antioxidant, antiseptic, anti-cancer, immunostimulator, and anti-microbial activity. Besides all herbs, clove and licorice containing mouthwash has more benefits than other herbal mouthwashes.

Herbal mouthwashes are gentle enough for daily use and provide less abrasive alternative to more potent prescription formulations meant for short term use. Herbal mouthwashes do not contain any alcohol and other preservatives that cause dry mouth. Herbal mouthwashes are suitable for oral prophylaxis. As it contains herbs and its extracts, that can maintain good oral hygiene without causing any toxic effect to our body. For daily use, herbal mouthwashes are more preferable than chlorhexidine mouthwash considering its side effects on long term usage.

A. vera mouthwash, mixture of Terminalia chebula and cinnamon, mixture of Staphysagria, Chamomilla, Echinacea, Plantago, Ocimum, and cistus extracts, mouthwashes with turmeric, neem and triphala, mixture of Acacia Arabica, Punica granatum, Chameli leaves, Glycyrrhiza glabra and neem shows significant reduction of plaque indices and gingival scores comparatively to chlorhexidine mouthwash and can be a better alternative to chlorhexidine mouthwash [1,33,34].

\section{Comparative study on chlorhexidine versus herbal}

Some salivary micro floras like $S$. mutans play an important role in initiation and progression of dental caries [35,36]. Although chlorhexidine has anti-microbial activity and good choice for effective plaque control by dentist in clinics, it cannot be used for long duration because it has various side effects such as taste alteration, supragingival calculus formation and desquamation of oral mucosa and also restricted usage in pediatric patients $[37,38]$. It also causes extrinsic staining while using beverages like tea and coffee [33]. Numerous studies have been conducted in comparison of chlorhexidine with herbal mouthwash. Although the herbal mouthwashes is less effective than chlorhexidine mouthwash, it can be used as a good oral prophylaxis as it does not has any adverse effects. Some herbal mouthwashes contains herbal extracts from $T$. chebula, A. vera, Azadirachta indica, pipe betle, O. sanctum, cinnamon and $T$. chebula extract in combination, green tea, peppermint satva, triphala, neem, pomegranate extracts, guava extracts, propolis, alum, darim leaves, mulethi, etc., are similar to chlorhexidine mouthwash in plaque control. Many herbal mouthwashes contains anti-inflammatory, anti-microbial, and anti-oxidant properties which enhances oral hygiene comparatively with chlorhexidine mouth wash.

Table 1: Herbal mouth rinse contains herbs with anti-inflammatory property

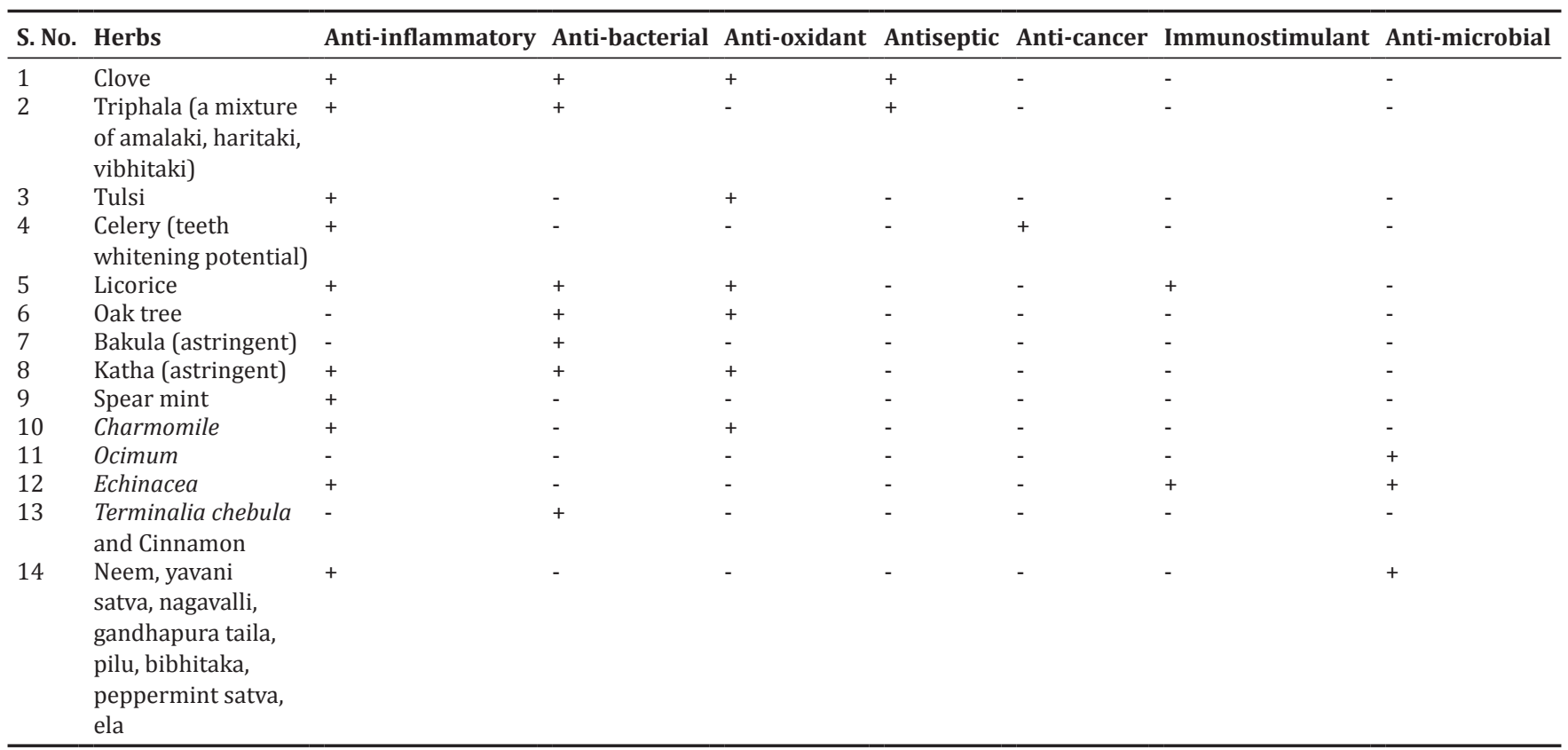


Some herbal mouthwash with chamomile extract kills pathogens such as staphylococcus candida species. A study provides a comparison between chlorhexidine and herbal mouthwash. Nearly $0.2 \%$ of CHXG causes brown staining of teeth, desquamation of oral mucosa and irritation in mouth which was not observed with herbal mouthwash containing $20 \%$ of babool chaal, $10 \%$ of darim leaves, $10 \%$ of chameli leaves as anti-microbial agent, 5\% mulethi as astringent, $2 \%$ neem and other contents such as alum, suhaga, kapoor, laung, and methanol. This mouthwash was a better alternative to $0.2 \%$ CHXG. Antigingivitis and plaque inhibiting properties of chlorhexidine and herbal mouthwash are similar [34]. Another study compared chlorhexidine with German chamomile and its extract produces 0.31 reduction in gingival index scores [37]. Nearly $50 \%$ of $T$. chebula which is antiplaque agent and 50\% cinnamon extract which has antibacterial and anti-fungal properties was compared with chlorhexidine. Reduction in plaque was noted. T. chebula extract is effective against Helicobacter pylori, Xanthomonas campestris pr.citri and Salmonella typhoid, herpes simplex virus Type-1, HIV-1. It has similar effect on plaque control and alters the oral flora [1]. Mixture of herbal extract from myrrh, Echinacea and chamomile inhibit the growth of $S$. mutans and Actinomyces viscosus. A. vera mouthwash contains vitamin C, hyaluronic acid, and dermatan sulfate which are involved in collagen synthesis and hence relief swelling and bleeding gums. It has a similar anti-plaque action to chlorhexidine [39]. Recent study on mixture of Staphysagria, Chamomilla, Echinacea, plantago, Ocimum, and cistus extracts used as mouth wash which was better than chlorhexidine in reducing salivary mutants streptococci count [33]. Herbal extracts such as chamomile retard biofilm formation and prevent gingival inflammation, Ocimum have anti-microbial effect on $S$. mutans, Echinacea which is an immunestimulator, anti-microbial, and antiinflammatory agent. Green tea mouthwash could reduce the aerobic mouth bacterial load and prevents plaque accumulation. It comes over halitosis due to infection of the bacteria and it is safe and non-toxic [40]. Many comparative studies have been conducted in benefits of herbal mouthwash with chlorhexidine mouthwash.

\section{SUMMARY}

Many studies have been conducted to compare chlorhexidine with many herbal extracts. Although herbal mouthwashes have the ability to maintain good oral hygiene on daily basis, still it is less effective than chlorhexidine mouthwash during treatments such as gingivitis, periodontitis, and trauma. Many herbal extracts contain similar antiplaque, anti-bacterial property with chlorhexidine mouthwash. Hence, it is most preferable than chlorhexidine for post-treatment prophylaxis because chlorhexidine has some adverse effects on long term use. Besides all herbal mouthwashes fruit extract containing mouthwash will be more effective against the microorganism present in the oral cavity without any side effect on over usage.

\section{CONCLUSION}

The aim of this review is to give an overview of mouthwashes and to compare the Chlorhexidine mouthwash with herbal mouthwash to aware people about the uses of herbal mouthwashes. Besides the disadvantages, chlorhexidine mouthwash plays effective role during dental treatments on short term usage. Herbal mouthwashes are suitable for maintaining good oral prophylaxis. Many programs have to be conducted to make them aware about mouthwashes in their oral hygiene.

\section{REFERENCES}

1. Gupta D, Nayan S, Tippanawar HK, Patil GI, Jain A, Momin RK, et al. Are herbal mouthwash efficacious over chlorhexidine on the dental plaque? Pharmacognosy Res 2015;7(3):277-81.

2. Loe H, Theilade E, Jensen SB. Experimental gingivitis in man. J Periodontol 1965;36:177-87.

3. Addy M. The use of antiseptics in periodontal therapy. In: Lindhe J, Karring T, Lang NP, editors. Clinical Periodontology and Implant Dentistry. $4^{\text {th }}$ ed. New Delhi: Jaypee Brothers Medical
Publishers (P) Ltd.; 2003.

4. Lyle DM. Chemotherapeutics and topical delivery systems. In: Wilkins EM, editor. Clinical Practice of the Dental Hygienist. $9^{\text {th }}$ ed. Philadelphia, PA: Wolters Kluwer Company; 2005. p. 439.

5. Biswas G, Anup N, Acharya S, Kumawat H, Vishnani P, Tambi S. Evaluation of the efficacy of $0.2 \%$ chlorhexidine versus herbal oral rinse on plaque induced gingivitis - A randomized clinical trail. IOSR J Nurs Health Sci 2014;3(2):58-63.

6. Rao NJ, Subhas KR, Kumar KS. Role of phytotherapy in gingivitis; A review. J Pharmacol 2012;8:1-5.

7. Aspalli S, Shetty VS, Devarathnamma MV, Nagappa G, Archana D, Parab P. Evaluation of antiplaque and antigingivitis effect of herbal mouthwash in treatment of plaque induced gingivitis: A randomized, clinical trial. J Indian Soc Periodontol 2014;18(1):48-52.

8. Malhotra R, Grover V, Kapoor A, Saxena D. Comparison of the effectiveness of a commercially available herbal mouthrinse with chlorhexidine gluconate at the clinical and patient level. J Indian Soc Periodontol 2011;15(4):349-52.

9. Mhaske M, Samad BN, Jawade R, Bhansali A. Chemical agents in control of dental plaque in dentistry: An overview of current knowledge and future challenges. Adv Appl Sci Res 2012;3(1):268-72.

10. CDC. In: Mangram AJ, Horan TC, Pearson ML, Silver LC, Jarvis WR, editors. Guideline for Prevention of Surgical Site Infection. United States: CDC; 1999

11. Thomas G, Bochicchio G, Napolitano LM, McCarter RJ, Roghman MC. Prophylactic chlorhexidine oral rinse decreases ventilator-associated pneumonia in surgical ICU patients. Surg Infect 2001;2(1):5-18.

12. Jenkins $S$, Addy $M$, Wade W. The mechanism of action of chlorhexidine. A study of plaque growth on enamel inserts in vivo. J Clin Periodontol 1988;15(7):415-24.

13. Leikin JB, Paloucek FP, editors. Chlorhexidine gluconate. Poisoning and Toxicology Handbook. 4th ed. New York: Informa; 2008. p. 183-4.

14. Health Organization. WHO Guidelines on Hand Hygiene in Health Care. Geneva: WHO; 2009.

15. Mohammadi Z, Abbott PV. The properties and applications of chlorhexidine in endodontics. Int Endod J 2009;42(4):288-302.

16. Hibbard JS. Analyses comparing the antimicrobial activity and safety of current antiseptic agents: A review. J Infus Nurs 2005;28(3):194-207.

17. Mathur S, Mathur T, Srivastava R, Khatri R. Chlorhexidine: The gold standard in chemical plaque control. Natl J Physiol Pharm Pharmacol 2011;1(2):45-50.

18. Zadik Y. Algorithm of first-aid management of dental trauma for medics and corpsmen. Dent Traumatol 2008;24(6):698-701.

19. Zadik Y, Yitschaky O, Neuman T, Nitzan DW. On the self-resolution nature of the buccal bifurcation cyst. J Oral Maxillofac Surg 2011;69(7):e282-4.

20. Neeraja R, Anantharaj A, Praveen P, Karthik V, Vinitha M. The effect of povidone-iodine and chlorhexidine mouth rinses on plaque Streptococcus mutans count in 6-to 12-year-old school children: An in vivo study. J Indian Soc Pedod Prev Dent 2008;26 Suppl 1:S14-8.

21. Walsh LJ. Preventive dentistry for the general dental practitioner. Aust Dent J 2000;45(2):76-82.

22. Farah CS, MacIntosh L, MacCollough LJ. Mouthwashes. Australian 2009;32(6):162-4.

23. PrasadKA, John S, Deepika V, Dwijendra KS, Reddy BR, Chincholi S.Antiplaque efficacy of herbal and $0.2 \%$ chlorhexidine gluconate mouthwash: A comparative study. J Int Oral Health 2015;7(8):98-102.

24. Mittal P, Gupta V, Kaur G, Garg AK, Singh A. Phytochemistry and pharmacological activities of Psidium guajava: A review. Int J Pharm Sci Res 2010;1(9):9-19.

25. Vasconcelos LC, Sampaio FC, Sampaio MC, Pereira Mdo S, Higino JS, Peixoto MH. Minimum inhibitory concentration of adherence of Punica granatum Linn (pomegranate) gel against S. mutans, S. mitis and C. albicans. Braz Dent J 2006;17(3):223-7.

26. Seeram NP, Adams LS, Henning SM, Niu Y, Zhang Y, Nair MG, et al. In vitro antiproliferative, apoptotic and antioxidant activities of punicalagin, ellagic acid and a total pomegranate tannin extract are enhanced in combination with other polyphenols as found in pomegranate juice. J Nutr Biochem 2005;16(6):360-7.

27. Chidambara Murthy KN, Jayaprakasha GK, Singh RP. Studies on antioxidant activity of pomegranate (Punica granatum) peel extract using in vivo models. J Agric Food Chem 2002;50(17):4791-5.

28. Battino M, Bullon P, Wilson M, Newman H. Oxidative injury and inflammatory periodontal diseases: The challenge of anti-oxidants to free radicals and reactive oxygen species. Crit Rev Oral Biol Med 1999;10(4):458-76.

29. Menezes SM, Cordeiro LN, Viana GS. Punica granatum (pomegranate) 
extract is active against dental plaque. J Herb Pharmacother 2006;6(2):79-92.

30. Jhakukreja B, Dodwad V. Herbal mouthwashes - A gift of nature. Int J Pharm Bio Sci 2012;3(2):46-52.

31. Biswas NP, Biswas AK. Evaluation of some leaf dusts as grain protectant against rice weevil Sitophilus oryzae (Linn). Environ Ecol $2005 ; 23(3): 485-8$

32. Weiss EI, Lev-Dor R, Kashamn Y, Goldhar J, Sharon N, Ofek I. Inhibiting interspecies coaggregation of plaque bacteria with a cranberry juice constituent [published erratam appear in J Am Dent Assoc 1999 Jan;130(1):36 and 1999 Mar;130(3):332]. J Am Dent Assoc 1998;129(12):1719-23.

33. Mehta S, Pesapathy S, Joseph M, Tiwari PK, Chawla S. Comparative evaluation of a herbal mouthwash (Freshol) with chlorhexidine on plaque accumulation, gingival inflammation, and salivary Streptococcus mutans growth. J Int Soc Prev Community Dent 2013;3(1):25-8.

34. Parwani SR, Parwani RN, Chitnis PJ, Dadlani HP, Prasad SV. Comparative evaluation of anti-plaque efficacy of herbal and $0.2 \%$ chlorhexidine gluconate mouthwash in a 4-day plaque re-growth study. J Indian Soc Periodontol 2013;17(1):72-7.
35. Agarwal P, Nagesh L; Murlikrishnan. Evaluation of the antibacterial activity of various concentrations of Tulsi (Ocimum sanctum) extract against Streptococcus mutans: An in vitro study. Indian J Dent Res 2010;21(3):357-9

36. Vyas YK, Bhatnagar M, Sharma K. In vitro evaluation of antibacterial activity of an herbal dentifrice against Streptococcus mutans and Lactobacillus acidophilus. Indian J Dent Res 2008;19(1):26-8.

37. Pourabbas R, Delazar A, Chitsaz MT. The effect of german chamomile mouthwash on dental plaque and gingival inflammation. Int J Pharm Res 2005;2:105-9.

38. Eley BM. Antibacterial agents in the control of supragingival plaque A review. Br Dent J 1999;186(6):286-96.

39. Gupta RK, Gupta D, Bhaskar DJ, Yadav A, Obaid K, Mishra S. Preliminary antiplaque efficacy of Aloe vera mouthwash on 4 day plaque re-growth model: Randomized control trial. Ethiop J Health Sci 2014;24(2):139-44.

40. Moghbel A, Farjzadeh A, Aghel N, Agheli H, Raisi N. The effect of green tea on prevention of mouth bacterial infection, halitosis, and plaque formation on teeth. Iran J Toxicol 2011;5(14):502-15. 